\title{
História, memórias e identidade entre os Xukuru do Ororubá
}

\author{
Edson Silva
}

Resumo: A história e as memórias Xukuru do Ororubá (Pesqueira/PE) são pontuadas por marcos históricos por eles eleitos como fundantes. A análise de narrativas colhidas por meio de entrevistas nos permite perceber como acontecimentos históricos foram relidos pelos Xukuru em determinados contextos e situações, também, como a essas leituras foram atribuídos significados para a afirmação da identidade indígena.

Palavras-chave: História indígena; memórias Xukuru; Nordeste do Brasil.

\begin{abstract}
The history and memories of the Xukuru do Ororubá (Pesqueira/Pernambuco) are shown by historical milestones which they have elected as foundations. The analysis of narratives collected through interviews allows us to perceive how historical events were re-read by the Xukuru in certain contexts and situations, also how these re-readings were given significance for the affirmation of indigenous identity.
\end{abstract}

Key words: Indigenous history; Xukuru memories; Brazilian northeast.

Doutorando em História Social da Cultura na UNICAMP. Mestre em História pela UFPE. Leciona História no Centro de Educação do Colégio de Aplicação-UFPE. Pesquisador na temática história indígena.

edson.edsilva@gmail.com 


\section{Os Xukuru do Ororubá}

O povo Xukuru habita a Serra do Ororubá, no Município de Pesqueira, a $215 \mathrm{~km}$ do Recife, na Região Agreste em Pernambuco. Um levantamento realizado em 2006 pela Fundação Nacional de Saúde contabilizou a população Xukuru em 9.021 indivíduos (FUNASA/SIASI), morando em 24 aldeias espalhadas pela Serra. Além disso, aproximadamente 200 famílias habitam no Bairro "Xukurus" e em outros bairros da cidade de Pesqueira (Almeida, 2000, p.52).

A colonização portuguesa na região onde habitam os Xukuru ocorreu a partir de 1654, quando o rei de Portugal fez doações de grandes sesmarias de terras a senhores de engenho do litoral para criação de gado. Em 1661, atendendo solicitação oficial, os Oratorianos fundaram o Aldeamento do Ararobá de Nossa Senhora das Montanhas, onde também possui fazendas de gado utilizando a mão-de-obra indígena (Medeiros, 1993). Conforme previa a legislação portuguesa, com o Diretório do Marquês de Pombal de 1757, o antigo Aldeamento do Ararobá foi elevado em 1762 à categoria de Vila com o nome de Cimbres. Em 1880 a sede do município foi transferida para Pesqueira e Vila de Cimbres passou a condição de distrito.

As terras do antigo aldeamento de Cimbres foram ao longo do tempo sendo invadidas por arrendatários que se apossavam das terras indígenas. No Século XIX aumentaram as invasões das terras indígenas pelos antepassados das famílias tradicionais em Pesqueira. Com a Lei de Terras em 1850, esses invasores e as autoridades provinciais passaram a pedir ao Governo Imperial a extinção do aldeamento Xukuru. A Câmara de Pesqueira em ofícios endereçados as autoridades provinciais, alegando que já não existiam mais índios Xukuru e sim caboclos e da necessidade de expansão do Município, requeria continuadamente as terras indígenas como patrimônio. Atendendo às insistentes solicitações, em 1879 o Governo Imperial decretou oficialmente a extinção do Aldeamento de Cimbres. Foram favorecidos os arrendatários, muitos deles vereadores e fazendeiros invasores das terras Xukuru, membros da elite local com consideráveis relações e influências na política provincial e nacional.

Fugindo das perseguições, famílias Xukuru se dispersaram pela região, ou foram morar em terras de outros ex-aldeamentos e nas periferias das cidades. D. Josefa recordou que os seus antepassados contavam como foram enganados com bebida e perseguidos se dispersaram,

Meu pai também contava, meu avô também contava. Naquele tempo todo mundo tinha suas terras. E os brancos fazia o quê? Os brancos 
pegava dava uma garrafinha de cachaça para os índios, os índios inocente, não é? Dava uma garrafa de cachaça para os índios, os índios ficava bêbado, depois jurava de morte, os bichinhos fugia tudo, eles tomava conta das terras toda. Foi assim que aconteceu. Por isso que está tudo pelo meio do mundo, uns na cidade, outros longe, outros em São Paulo, meus irmãos mesmos estão tudo em São Paulo (1).

Outras famílias que foram discriminadas ao serem chamadas de "caboclos do Orubá", resistiram em pequenas glebas de terras, sítios em locais de difíceis acessos, ou ficaram trabalhando em suas próprias terras, exploradas como mão-de-obra pelos fazendeiros, invasores do território indígena, como relatou o Pajé Xukuru "Seu Zequinha”,

Agora tinha um fazendeiro, um fazendeiro não, um capitão. Chamava-se Capitão Américo, que veio pedir uma queimadinha para plantar cabaço para fazer cuias para os escravos, que ele tinha uma senzala de negro. Para fazer cuia para os negros comerem dentro das cuias, dentro dos batedor. Ele disse, "olha caboclo, aonde eu queimar é meu, não é?". Aí o caboclo pensou que era... chamava caboclo, para diminuir já, não chamava mais indio. Ele disse "é tá certo, onde queimar...". Danou fogo, sem fazer acerto, sem fazer nada, o fogo veio sair perto de Cana Brava. Aí ele disse "aqui tudo é meu", sabedoria! Ele ameaçou os índios, aí tomou tudo, tomou. Isso não dá nada, não dá nada, parece que dá uns 5 mil hectares por aí, oxente dá muito mais, dá uns 10 mil hectares! Aí ele passou a mão até tomar... Américo, Capitão Américo na época. Aí disse que hoje os familiares dele tomaram até Capim de Planta que chamavam... a Serra toda, para chegar em Cana Brava, tudo era dele! Agora eles venderam a outros proprietários, os tempos passaram eles venderam para outras pessoas (2). (grifamos).

Entre os fins do Século XIX e nas primeiras décadas do Século XX, encontravam-se índios Xukuru dançando o Toré na Vila de Cimbres, como registrou o historiador Pereira da Costa no seu Vocabulário Pernambucano. Em 1935 o jornalista Mário Melo publicou o artigo "Etnografia pernambucana: os xukurus de Ararobá", na Revista do Instituto Arqueológico, Histórico e Geográfico de Pernambuco (IAHGP), onde afirmava a presença de famílias Xukuru em Cimbres, inclusive com falantes da língua indígena. Mário Melo afirmou que recebera informações do sertanista Curt Nimuendajú que recentemente "estivera em contacto com os descendentes dos xucurus" (Melo, 1935, p.44).

Escreveu ainda Melo, “Existem ainda cerca de 50 indivíduos, já cruzados alguns, porém que conservam estigmas dos ameríndios, como tais facilmente reconhecíveis, apesar de ausência completa de semelhança com o mongol". O autor pernambucano fez uma comparação com os índios Carnijós de Águas Belas, acentuando que contrariamente aqueles 
os de Cimbres "vivem desagrupados" e que "já não conservavam tradições, nem religião". "Quase que perderam a língua", mas guardavam ainda algumas palavras, faladas com o português "em forma de gíria".

Sobre a religião Mário Melo escreveu que se tratava de "uma espécie de idolatria, por infiltrações do catolicismo". E ainda, "Sabem, perfeitamente, que descendem da tribu xucurú, que ocupou aquela região, tem orgulho da sua procedência e julgam superiores aos outros habitantes, guardando rancor dos brancos por lhes haverem tomado as terras". (Ibidem, 1935). Depois de citar informações históricas da formação "Aldeia do Ararobá", Melo destacou a importância das investigações de Nimuendajú em razão da "identificação dos remanescentes indígenas", criando um neologismo para expressar sua visão sobre a situação: ocorria uma "defamiliarização".

O então conhecido jornalista Mário Melo, também Secretário Perpétuo e editor Revista do IAGHP, afirmou ao longo do texto e nas conclusões do seu artigo a necessidade de estudar "os remanescentes indígenas" que estavam "desaparecendo sem deixar vestígios", em localidades do Agreste e Sertão pernambucano. Fazendo comparações entre o primitivo/ degenerado, o bárbaro/moderno, o autor expressou nesse e em demais artigos publicados na imprensa pernambucana, uma perspectiva que via os índios como vítimas do progresso inerente à civilização. Uma civilização naturalmente construída sobre as ruínas de grupos inadaptáveis. Civilização da qual o próprio autor se julgava um representante, um observador como estudioso dos "remanescentes" de índios, os caboclos em degeneração.

Mesmo após a decretação oficial do fim do Aldeamento e diante das proibições, perseguições e violências coloniais, os Xukuru praticaram seus cultos religiosos que eram realizados às escondidas. Nas primeiras décadas do século $X X$, os Xukuru assim como outros povos indígenas no Nordeste, retomaram com mais vigor a mobilização pela posse de suas terras e garantia de seus direitos, pressionando as autoridades do Serviço de Proteção ao Índio/SPI. O primeiro relatório oficial contemporâneo sobre os Xukuru data de 1944 e foi feito por Cícero Cavalcanti, sertanista a serviço do SPI (Antunes, 1973, p.40-43).

Nesse Relatório o sertanista citou os Xukuru como moradores em várias localidades na Serra do Ororubá e que os "caboclos mais velhos" por se reunirem para realização dos seus rituais, eram denunciados à polícia como catimbozeiros pelos "brancos", os fazendeiros invasores nas terras indígenas. Líderes dos cultos indígenas foram intimados a comparecer à Delegacia e os índios estavam proibidos pela polícia de prati- 
car "o segredo" do Ouricuri. Os invasores das terras indígenas procuravam reprimir as expressões de afirmação da identidade indígena a qualquer custo. Outros indígenas foram denunciados tendo as autoridades policiais "os proibido de curatórias". O sertanista afirmava, ainda, que "alguns costumes Xukurus ainda vivem em seu coração". O Toré era dançado na Festa de Nossa Senhora das Montanhas, em Cimbres.

Em 1954 foi instalado um Posto do SPI na Serra do Ororubá. Uma conquista dos Xukuru, mas que não solucionou os conflitos com os fazendeiros invasores de suas terras. Isso porque a política do órgão indigenista oficial para o Nordeste foi baseada no discurso da falta de comprovação documental/jurídica de territórios indígenas, compensada pela redução de áreas pretendidas ou a aquisição de pequenas glebas de terras. $\mathrm{Ou}$ seja, em um modelo de ação de "insularização" das populações indígenas em "ilhas" geridas pelo SPI, cercadas por não-índios, como no caso dos Xukuru (Peres, 1992, p.126-127).

A partir dos anos 1990 os Xukuru passaram a se autodenominar Xukuru do Ororubá. Eles afirmam terem escolhido essa denominação para não serem confundidos pelos não-índios (leia-se a imprensa e a sociedade em geral) com um outro povo indígena, os Xukuru-Kariri que estão, em sua a maioria, aldeados no Município de Palmeira dos Índios/ AL.

\section{As memórias como fontes para a história Xukuru}

Só recentemente os povos indígenas no Brasil vem sendo objeto de pesquisa e reflexão por parte de historiadores/as. Atualmente com uma "nova história indígena", onde pesquisadores/as a partir do diálogo com categorias de análises antropológicas sobre a cultura e as relações coloniais, com um novo olhar que supera as tradicionais visões eurocêntricas, etnocêntricas e evolucionistas, têm elaborado uma considerável produção sobre a história desses povos. Essas pesquisas no Nordeste apesar de serem ainda tímidas em termos quantitativos, colocam em xeque abordagens que afirmam o desaparecimento e a inexistência de povos indígenas na Região.

Os povos indígenas deixados à margem por uma história colonial e triunfalista, que assim como outros grupos de marginalizados foram sempre discriminados nos documentos oficiais, que tiveram pouco acesso e domínio da escrita, têm nas fontes orais um lugar privilegiado para a pesquisa. Nesse sentido é que,

(...) o uso das fontes orais permite não apenas incorporar indivíduos ou coletividades até agora marginalizados ou pouco representados 
nos documentos arquivísticos mas também facilita o estudo de atos e situações que a racionalidade de um momento histórico concreto impede que apareçam nos documentos escritos. Assim, portanto, as fontes orais possibilitam incorporar não apenas indivíduos à construção do discurso do historiador mas nos permite conhecer e compreender situações insuficientemente estudadas até agora. 2 (Alcazar i Garrido, set.92/ago.93, p. 36).

As memórias, os relatos orais indígenas, no caso aqui dos Xukuru do Ororubá são, portanto, importantes fontes de pesquisa, possibilitando compreender as visões que os próprios indígenas têm da história, as leituras que eles fazem de acontecimentos, da dinâmica das relações sociais, etc. Assim é que um entrevistado em seu depoimento " nos revela pedaços do passado, encadeados em um sentido no momento em que são contados e em que perguntamos a respeito", uma "recuperação do vivido conforme concebido por quem viveu" (Alberti, 2004, p.15). Foram selecionados a seguir alguns trechos de relatos indígenas para reflexões.

\section{Memórias sobre a Guerra do Paraguai}

Entre os índios no Nordeste encontramos diversos relatos da participação de seus antepassados na Guerra do Paraguai, a exemplo dos Xukuru do Ororubá que expressam em muitos relatos orais, suas memórias sobre aquele conflito. Nas narrativas dos Xukuru são lembrados enfaticamente "os 30 do Ororubá", combatentes que se destacaram em uma das batalhas na Guerra do Paraguai,

Eu ouvi falar assim, é uma história nossa que nós temos dizendo que os Xukuru foram para a Guerra do Paraguai brigarem. Foram 30, morreram 12, voltaram 18. Então eu ouvi falar, então foi os índios do Brejinho, não lembro nem aonde mora, nem o nome deles. Eles são da família dos Nascimento, lá na Aldeia Brejinho. E foi mais uns outros de outras aldeias Xukuru, e foi uma índia chamada Maria Coragem também. E lá eles brigaram na Guerra... aí levaram a bandeira... e pediram para eles irem buscar. Então, eles foram, eles já tinham passado... E eles chegaram na beira do rio, e eles já tinham atravessado o rio, eles entraram no mato, cortaram madeira, cortaram cipó, fizeram um barco, foram lá, cortaram tudo de facão e trouxeram a bandeira para a Princesa Isabel.2

Sobre o relatado acima, um pesquisador escreveu que o fato ocorreu durante a Batalha de Tuiuti, um dos maiores embates da Guerra do Paraguai quando,

O inimigo arrebatou a bandeira dos "30 de Voluntários", batalhão integrado pelos nossos índios xucurus. O Comandante, Ten.cel. 
Apolônio Peres Cavalcanti Jácome da Gama, em assomo de desapontamento, bradou para os seus soldados (os nossos índios) que retomassem a bandeira e pouco depois a companhia de guerra que partira no cumprimento da ordem, regressava reduzida a 10 ou 12 homens trazendo o nosso pavilhão a despeito de quase transformado em farrapos (Maciel, 1980, p.116).

Os Xukuru relatam também que os seus antepassados voltaram com condecorações da Guerra do Paraguai: "O Irmão da Hora trouxe um terno, de reis. Digo, porque o terno eu vi. De coroa, galão e todo, porque ganhou esse prêmio Irmão da Hora, Antonio Molecão e Antonio Tavarinho" (4). Em seus relatos, os indígenas falam ainda de quépes, medalhas, espadas, "diplomas da Guerra", roupas e outros adereços militares, além dos "títulos de terra", trazidos pelos que retornaram da Guerra. Como disse ainda um entrevistado:

Da Guerra do Paraguai o que eles trouxeram espada, trouxeram coturno, trouxeram estrela e um major Candinho eles foi Chefe de Posto aqui dentro e levou essas coisas, essas coisas ninguém sabe onde elas estão, se estão em museu, se estão no Exército. É uma história que estou contando porque a gente ouviu falar, mas não sentou aquela pessoa para me dizer à verdade sobre a Guerra do Paraguai (4).

A partir das leituras da participação de seus antepassados na Guerra do Paraguai, os Xukuru afirmam que "eles venceram a guerra", o que lhes garante o direito às suas terras, como relatou um dos entrevistados,

Chamavam o número Trinta dos Voluntários. Chama os Trinta dos Voluntários porque foram pro Paraguai, lutaram na guerra lá, venceram... mas quando veio de volta, passaram no Rio de Janeiro, o rei e a rainha não tinham com que agradecer a eles e disse: 'vocês faça sua divisão de terra, é patrimônio que eu vou assinar pra vocês" (3). (grifamos).

D. Josefa também falou sobre o significado da participação de seus antepassados na Guerra do Paraguai,

A pessoa que foi para a Guerra, naquele tempo eu não era nascida, eu sei contar coisa assim, alguma coisa que eu já ouvi meu avô falar, meu pai. Os parentes deles foram para a Guerra, lutaram, venceram a Guerra. E depois que eles lutaram e venceram a Guerra, a Princesa Isabel queria dar dinheiro para eles. D. Pedro disse "não dê, porque eles são inocentes, os brancos vão roubar o dinheiro, a terra deles. Dê terra a eles, não dê dinheiro, não". Aí ela foi e deu a terras a eles.

Ganharam aquela roupa de ouro, com aqueles botão de ouro, aquele chapéu, aquelas coisa, não é? E ganharam a terra também. O principal foi a terra que justamente essa terra que ainda hoje estão lutando, querendo acabar com os índios, sabendo que a terra é dos índios porque foi ganha. Está lá no Rio de Janeiro, essa cópia das terras está no Rio de Janeiro (1). 
Ou ainda, como aparece de forma mais explícita na fala do ViceCacique Xukuru,

Olhe, a dádiva que da Guerra foi oferecido dinheiro e ouro. Só que para os índios, dinheiro e ouro não eram interessantes, interessante era a terra. Aí eles disseram que ao invés de ouro eles queriam uma coisa que nunca se acabasse, que era a terra que estava na mão de algumas pessoas que não deixavam eles trabalhar. Então, eles queriam a terra para eles viverem, os filhos deles viverem e os filhos dos filhos deles. Isso aí foi o pagamento que eles receberam, que eles pediram (5). (grifamos).

Outros povos indígenas que também participaram da Guerra do Paraguai recorreram às memórias da participação dos seus antepassados naquele conflito, como forma de afirmação de seus direitos as terras. A exemplo dos Terena (MS) que assim como outros povos da região de Dourados voluntariamente se incorporaram na Guarda Nacional, como forma de se livrarem das ameaças de fazendeiros. Os Terena reivindicaram inclusive as autoridades militares o direito de terem armas assim como os demais soldados e diante da negativa recebida, invadiram e se apropriaram das armas do arsenal da Vila de Miranda (Vargas, 2003, p.53-54).

Finda a Guerra, além da depopulação indígena em decorrência dos combates e de doenças, os índios que retornaram encontraram suas terras invadidas por fazendeiros, o que provocou a desterritorialização Terena. Muitos ex-combatentes receberam do Governo Imperial patentes militares. Caciques passaram oficialmente a Capitão, título que ostentavam com orgulho juntamente com a fotografia do Imperador, a quem chamavam de amigo. Mas se a transformação do antigo chefe indígena em capitão fora uma tentativa governamental de desestruturar a organização tradicional indígena, quando os índios chamavam o Imperador de amigo se consideravam em situações de igualdade com todos os demais súditos brasileiros e, portanto com os mesmos plenos direitos, inclusive as terras indígenas (Idem, p.55).

Os Terena passaram a reivindicar do Governo a demarcação dos seus territórios e ressignificaram as patentes militares e principalmente os títulos de Capitão, que foram utilizados junto ao poder oficial como exigências para a posse de suas terras (Id., p.58). Os índios pediram e receberam das autoridades provinciais além de ferramentas, fardamentos como brindes durante a Guerra do Paraguai. Para os Terena as fardas e as patentes militares além de diferenciá-los das outras etnias, os colocavam em igualdade com os brancos. Nos encontros com as autoridades os índios iam vestidos com os fardamentos e enfatizavam seus títulos, lembravam os serviços prestados ao Estado como troca pelos seus direitos reivindicados (Id, p.73). Os Terena vivenciaram uma outra guerra com os 
fazendeiros e com as autoridades para reconquista de seus antigos domínios territoriais.

A partir dos relatos indígenas sejam Terena ou Xukuru, é possível perceber as leituras que indígenas fazem sobre a participação de seus antepassados na Guerra do Paraguai. Dentre outros significados há o de afirmarem ser herdeiros de uma "vitória no Paraguai". Vitória transmudada, também, na certeza em vencer a guerra em muitas batalhas por suas terras, pela reivindicação e reconhecimento de seus direitos históricos que lhes garantem o futuro.

\section{Os tempos do SPI}

Os povos no Nordeste, como já foi dito, ao tomarem conhecimento da existência de um órgão federal, o SPI fundado em 1910 para prestar assistência aos índios, iniciaram uma mobilização para obterem o reconhecimento pelo Estado brasileiro. Na memória oral Xukuru, encontramos relatos dessa mobilização contemporânea pelo reconhecimento oficial.

Os Xukuru contam, a exemplo do relato abaixo, que após procurarem ajuda financeira do padre de Bom Conselho, três índios foram a pé ao Rio de Janeiro encontrarem-se com o Marechal Rondon, fundador do SPI,

Aí eu disse: - Vocês vão lá, chegar em Bom Conselho, tem um padre chamado beneditinos, ele protege o índio de Águas Belas, de Palmeira dos Índios. Esse padre é muito bom... vocês se entendem com ele que ele dá mais uma proteção, conhece Cândido Rondon. Aí arranjei uns dinheiro, o padre vai dá 500 mil réis. Esses homens saíram daqui no $1^{\circ}$ de outubro de 1953 e chegaram no Rio de Janeiro no dia $1^{\circ}$ de janeiro de 1954. Levaram três meses. Foram de pés. Passaram 90 dias de viagem (6).

As viagens dos indígenas para capital na tentativa de falar com as autoridades provinciais, ou as viagens ao Rio de Janeiro para conseguir uma audiência com o Imperador, na busca pela garantia de seus direitos, ocorreram desde o século XIX. Na documentação da Diretoria dos Índios de Pernambuco existem registros de viagens de Manuel Valetim ao Rio de Janeiro. Líder dos índios no Riacho do Mato, que foram transferidos da extinta Aldeia da Escada e estavam sendo perseguidos por grandes posseiros invasores do novo local a eles destinados, Valentim foi à Corte reclamar os direitos de seus parentes indígenas (Silva, 1995).

Com a ida ao Rio de Janeiro além do reconhecimento oficial, os Xukuru conquistaram o direito à instalação de um Posto do SPI em suas terras. Um passo político decisivo diante das perseguições dos fazendeiros 
invasores do território indígena, como já afirmara em seu Relatório de 1944 o sertanista Cícero Cavalcanti.

\section{Os tempos do Cacique "Xicão"}

Em fins dos anos 1980 após a participação na campanha da Constituinte, com a atuação marcante do Cacique "Xicão", os Xukuru retomam à mobilização por seus direitos. Motivados pelas conquistas na Constituição de 1988 e contando com o apoio de outros povos indígenas no Nordeste e de setores da sociedade civil, como o Conselho Indigenista Missionário/CIMI, órgão da Igreja Católica/CNBB, os Xukuru iniciaram a retomada de seu território tradicional, reocupando áreas de várias fazendas até então nas mãos de posseiros.

O acirramento dos conflitos entre os "Xucurus" e fazendeiros que eram posseiros nas terras então reivindicadas pelos indígenas, entre os fins dos anos 1980 e meados dos anos 1990, foi motivo de extensas reportagens publicadas no Diário de Pernambuco, no Jornal do Comercio ambos do Recife e no jornal Folha de São Paulo. Enquanto os fazendeiros negavam a presença de índios "puros" ou a ocorrência dos conflitos, os Xukuru denunciavam as violências, a miséria e a fome em razão de terem suas terras invadidas por grandes criadores de gado.

Na mobilização Xukuru na década de 1980, destacou-se Francisco de Assis Araújo, o Cacique "Xicão", como era conhecido. Além de ser uma liderança carismática para o seu povo, foi também uma expressiva e reconhecida liderança entre os demais povos indígenas no Nordeste, alcançando, ainda, uma considerável projeção no movimento indígena no país. Sob sua liderança os Xukuru pressionaram os órgãos públicos pelo reconhecimento de seus direitos e a demarcação de suas terras. A atuação do Cacique Xicão provocou a ira dos fazendeiros, a oligarquia de Pesqueira, tradicionais invasores das terras Xukuru, financiadores de um pistoleiro que assassinou o Cacique em 20 de maio de 1998.

A atuação do Cacique Xicão foi bastante significativa para o povo Xukuru, já que sob sua liderança as áreas do território indígena retomadas das mãos dos fazendeiros, permitiram que os indígenas pudessem plantar e colher superando a miséria e a fome de anos, voltarem a ter dignidade. Por isso e em razão de Xicão ter sido assassinado de forma brutal, "Mandaru", como ele é chamado pelos indígenas, é reverenciado como um herói do povo Xukuru. Na Festa anualmente celebrada em Cimbres dedicada a N. Sra. das Montanhas, a quem os Xukuru chamam de "Nossa 
Mãe Tamain", os índios dizem que a santa é uma cabocla que lhes apóia na luta pela terra. Depois da procissão os Xukuru entram no templo carregando o andor gritando "Viva Tamain, Pai Tupã e o Cacique Xicão" (Silva, 2002).

Xicão, portanto é bastante lembrado como expressou um dos nossos entrevistados,

(...) estava falando sobre o tempo em que aqui existia cacique da Funai, não tinha cacique, era cacique da Funai e até que nasceu o Cacique Xicão foi lutar por nós, foi assassinado...morreu por nós, não se vendeu a ninguém, certo? E estamos lutando para que o nosso povo seja liberto, na nossa área. Aqui chegou o tempo de nós trabalharmos aqui dentro das nossas terras... E hoje nós temos aqui, essa área aqui, nós temos muito trabalho do Cacique Xicão, a saudade é grande que nós temos, mas quando o Cacique Xicão levaram ele, que lá ou os fazendeiros achava que calando a boca do Cacique Xicão, calava a boca dos Xukuru, mas não. Nós nos unimos, nos organizamos e nasceu mais índio Xukuru" (3).

A $1{ }^{a}$ Assembléia do Povo Xukuru teve o tema "Em memória viva do Cacique Xicão", foi realizada na Aldeia Pedra D'Água de 18 a 20 de maio de 2001, três anos após o assassinato do seu líder. Os Xukuru discutiram a sua história e o processo de organização que vivenciavam naquele momento. A fala de uma das professoras que leu o resultado da discussão do seu grupo de trabalho foi veemente:

A força, organização e a mobilização dos Xukuru sobre os seus direitos: a partir de 86, Xicão assumiu a liderança da tribo e começou a organizar as aldeias, colocando em cada uma um representante, para mostrar os desejos e as necessidades de cada comunidade. Bem como, fez reuniões em todas as comunidades para conscientizar o povo de seus direitos e da importância de estarmos juntos para lutar e reivindicar. Para termos uma saúde, uma educação diferenciada e todos os nossos direitos respeitados (Palitot, 2003, p.89).

Após a leitura, a citada professora complementou com firmeza o texto lido anteriormente, enfatizando as formas de organização do povo Xukuru, incentivadas por Xicão e segundo ela "para que cada um de nós nos orgulhássemos de ser Xukuru e tivéssemos vontade de lutar pelos nossos direitos". E conclui sua fala dizendo "Então, hoje, nós estamos aqui graças a ele. Temos tudo. Tudo que nós temos e somos hoje, nós devemos agradecer ao nosso Cacique Xicão, que foi um grande guerreiro. Que nos deixou como exemplo a luta que cada um de nós tem por obrigação continuar" (Ibid., 2003).

A importância de Xicão para o povo Xukuru pode ser compreendida pela dimensão dos atos religiosos e políticos que anualmente vêm sendo 
realizados no dia 20 de maio, data de seu assassinato. No ato público que ocorre naquela data participam um considerável número de delegações de outros povos indígenas e parceiros da causa indígena. Os Xukuru visitam o túmulo do seu querido Cacique, que como eles falam "está plantado, para que dele nasça novos guerreiros" na mata da Aldeia Pedra D'Água. Participam de uma missa celebrada no local e em seguida caminham em um grande contingente da Serra do Ororubá até a Cidade de Pesqueira, para o Bairro Xukurus lugar onde o Cacique foi morto, onde realizam um grande ato público encerrando as manifestações daquele dia.

\section{História, memórias e identidade Xukuru}

A história Xukuru é pontuada por acontecimentos, marcos por eles considerados fundantes tais como: a Guerra do Paraguai, os tempos do SPI e os tempos de Xicão. Como foi visto, a participação dos Xukuru na Guerra do Paraguai foi e é relida em diferentes contextos. Em um deles foi o da reorganização e mobilização para retomada de suas terras nos anos 1980, sob a liderança do Cacique Xicão.

Questionado sobre qual foi a importância da participação dos seus antepassados na Guerra do Paraguai, o Pajé "Seu Zequinha", uma das figuras centrais no processo de reconhecimento dos marcos para o processo de demarcação do território Xukuru nos anos 1990 afirmou,

Foi importante porque na época aqui existia uns coronéis, uns capitães, uns tenentes. Só bastava, era o pessoal que podia comprava aquelas patentes de tenente, de capitão e aí massacrando os índios. Depois que eles vieram, melhorou. Trouxeram os títulos, aí eles não puderam... Eles tomavam a terra, eles tomavam, "aqui é meu, é meu e pronto, acabou-se" (2).

Observando-se as narrativas recentes das memórias Xukuru, constata-se que os acontecimentos passados também sãos relidos a partir dos “tempos do Cacique Xicão". Em Janeiro de 2002 ocorreu um conflito interno resultando em um faccionalismo entre os Xukuru. As disputas foram estimuladas por interesses políticos externos, provocando a dissidência de um grupo de famílias que foram expulsas após um atentado contra o atual Cacique Marcos, filho de Xicão.

Durante o tempo em que durou o conflito a memória sobre o Cacique Xicão, chamado "o Guerreiro da Paz", foi outra vez lembrada. As formas de organizações elaboradas no tempo de sua liderança foram enfaticamente recordadas como as únicas e legítimas, como garantia da unidade, pelo grupo majoritário que ficou no território. 
Compreender o significado das narrativas sobre o Cacique Xicão para os Xukuru é compreender a "história de experiências". Um debruçar sobre essas narrativas, possibilita entender como "pessoas ou grupos efetuaram e elaboraram experiências" (Alberti, 2004, p.25). Essas experiências foram e são marcantes, porque foram intensamente vividas. As narrativas do povo Xukuru nos ajudam ainda "entender como pessoas e grupos experimentaram o passado e torna possível questionar interpretações generalizantes de determinados acontecimentos e conjunturas" (Ibid., p.26).

Ainda sobre Xicão foi constatado que, "O Cacique assassinado tornou-se herói e mártir, foi reapropriado pelos índios passando a fazer parte do universo mítico e religioso do grupo. Sua memória tornou-se o elemento central da nova identidade Xukuru, fornecendo as motivações para a ação social e a legitimidade das organizações políticas que ajudou a construir e que, agora, são ameaçadas pela repressão e o faccionalismo" (Palitot, 2003, p.107).

Analisando os relatos Xukuru, é possível afirmar como disse Michael Pollak quando discutiu sobre memória e identidade social, que entre os Xukuru é "perfeitamente possível que por meio da socialização política, ou da socialização histórica, ocorra um fenômeno de projeção ou de identificação com determinado passado, tão forte que podemos falar numa memória quase herdada" (Pollak, 1992, p.2). As reflexões aqui apresentadas procuraram evidenciar como os Xukuru apoiados na memória e na história que compartilham sobre o passado, fazem à releitura de acontecimentos que escolheram como importantes, para construírem sua identidade, para afirmarem seus direitos como povo indígena Xukuru.

\section{Os relatos se referem às seguintes pessoas:}

1 Josefa Rodrigues da Silva. Aldeia Gitó, em 30/03/02. Serra do Ororubá, Pesqueira/PE.

2 Pedro Rodrigues Bispo, "Seu Zequinha", 72 anos, Pajé Xukuru. Bairro Portal, em 29/03/02. Pesqueira/PE.

3 João Jorge de Melo, 65 anos. Aldeia Sucupira, em 30/03/2002. Serra do Ororubá, Pesqueira/PE.

4 Malaquias Figueira Ramos, 62 anos. Aldeia Caípe, em 12/11/1996. Serra do Ororubá, Pesqueira/PE.

5 José Barbosa dos Santos, "Zé de Santa", 55 anos, Vice-Cacique Xukuru. Aldeia Santana, em 01/04/2002. Serra do Ororubá, Pesqueira/PE.

6 Durval Ferreira Farias, 84 anos. Bairro Xukurus, em Pesqueira/PE, maio de 1997. In: Memórias do Povo Xukuru. Olinda, Centro de Cultura Luiz Freire/CCLF, 1997, pp.33, dig. 


\section{Referências}

ALCÀZAR I GARRIDO, Joan Del. As fontes orais na pesquisa histórica: uma contribuição ao debate. Revista Brasileira de História, São Paulo, v.13, n.25/26, p.33-54, set.1992/ago.1993.

ALBERTI, Verena. Ouvir contar: textos em História Oral. Rio de Janeiro: FGV, 2004.

ALMEIDA, Eliene A. de. (Org.). Xucuru, filhos da mãe Natureza: uma história de resistência e luta. 2. ed. Olinda: CCLF/Pesqueira Prefeitura Municipal, 2002.

ANTUNES, C. Wakona-Kariri-Xucuru. Aspectos sócio-antropológicos dos remanescentes indígenas de Alagoas. Maceió: UFAL, 1973.

MEDEIROS, M. do C. Igreja e dominação no Brasil escravista: o caso dos Oratorianos de Pernambuco - 1659-1830. João Pessoa: Idéia, 1993.

MELO, Mário. Etnografia Pernambucana: os Xukurus de Ararobá. Revista do Instituto Arqueológico Histórico e Geográfico de Pernambuco, Recife, v. 33, p. 43-45, 1935.

PALITOT, Estevão Martins. Tamain chamou nosso Cacique: a morte do Cacique Xicão e a (re)construção da identidade entre os Xukuru do Ororubá. 2003. Monografia (Bacharelado em Ciências Sociais) - PPGS/UFPB, João Pessoa, 2003.

PEREIRA DA COSTA, F. A. Vocabulário pernambucano. 2.ed. Recife: Governo do Estado de Pernambuco, Secretaria de Educação e Cultura, 1976.

PERES, Sidnei. Arrendamento e terras indígenas: análise de alguns modelos de ação indigenista no Nordeste (1910-1960). Dissertação (Mestrado em Antropologia Social) - PPGAS-MN/UFRJ, Rio de Janeiro, 1992.

POLLAK, Michael. Memória e identidade social. Estudos Históricos, Rio de Janeiro, v.5, n.10, p.200-212, 1992.

SILVA, Edson. O lugar do índio. Conflitos, esbulhos de terras e resistência indígena no século XIX: o caso de Escada - PE (1860-1880). Dissertação (Mestrado em História) - PPGH/ UFPE, Recife, 1995.

. "Nossa Mãe Tamain": Religião, reelaboração cultural e resistência: o caso dos Xukuru do Ororubá (PE). In: BRANDÃO, Sylvana. (Org.) História das religiões no Brasil. Recife: EDUFPE, p. 347-362, 2002.

. Memórias Xukuru e Fulni-ô da Guerra do Paraguai. Ciências Humanas em Revista, São Luís, v.3, n.2, p.51-58, 2005.

VARGAS, Vera L. F. A construção do território Terena (1870-1966): uma sociedade entre a imposição e a opção. Dissertação (Mestrado em História) - PPGH/UFMS, Dourados, 2003.

Recebido em 02 de janeiro de 2007.

Aprovado para publicação em 24 de janeiro de 2007.

102 Edson SILVA. História, memórias e identidade entre os Xukuru do Ororubá. 